\title{
Recovering a lost baseline: missing kelp forests from a metropolitan coast
}

\author{
Sean D. Connell ${ }^{1, *}$, Bayden D. Russell ${ }^{1}$, David J. Turner ${ }^{2}$, Scoresby A. Shepherd ${ }^{3}$, \\ Timothy Kildea ${ }^{4}$, David Miller ${ }^{5}$, Laura Airoldi ${ }^{6}$, Anthony Cheshire ${ }^{7}$
}

\author{
${ }^{1}$ Southern Seas Ecology Laboratories DX 650 418, School of Earth and Environmental Sciences, University of Adelaide, \\ South Australia 5005, Australia \\ ${ }^{2}$ Regional Conservation, Department for Environment and Heritage, GPO Box 1047, Adelaide, South Australia 5001, Australia \\ ${ }^{3}$ South Australian Research and Development Institute (Aquatic Sciences), PO Box 120, Henley Beach, South Australia 5022, Australia \\ ${ }^{4}$ Australian Water Quality Centre, PMB 3, Salisbury, South Australia 5108, Australia \\ ${ }^{5}$ Coast \& Marine Conservation Branch, Natural and Cultural Heritage Directorate, Dept of Environment and Heritage, Keswick, \\ South Australia 5035, Australia \\ ${ }^{6}$ Università di Bologna, Via S. Alberto 163, 48100 Ravenna, Italy \\ ${ }^{7}$ Science to Manage Uncertainty, 24 Winding Way, Belair, South Australia 5052, Australia
}

\begin{abstract}
There is concern about historical and continuing loss of canopy-forming algae across the world's temperate coastline. In South Australia, the sparse cover of canopy-forming algae on the Adelaide metropolitan coast has been of public concern with continuous years of anecdotal evidence culminating in 2 competing views. One view considers that current patterns existed before the onset of urbanisation, whereas the alternate view is that they developed after urbanisation. We tested hypotheses to distinguish between these 2 models, each centred on the reconstruction of historical covers of canopies on the metropolitan coast. Historically, the metropolitan sites were indistinguishable from contemporary populations of reference sites across $70 \mathrm{~km}$ (i.e. Gulf St. Vincent), and could also represent a random subset of exposed coastal sites across $2100 \mathrm{~km}$ of the greater biogeographic province. Thus there was nothing 'special' about the metropolitan sites historically, but today they stand out because they have sparser covers of canopies compared to equivalent locations and times in the gulf and the greater province. This is evidence of wholesale loss of canopy-forming algae (up to $70 \%$ ) on parts of the Adelaide metropolitan coast since major urbanisation. These findings not only set a research agenda based on the magnitude of loss, but they also bring into question the logic that smaller metropolitan populations of humans create impacts that are trivial relative to that of larger metropolitan centres. Instead, we highlight a need to recognise the ecological context that makes some coastal systems more vulnerable or resistant to increasing human-domination of the world's coastlines. We discuss challenges to this kind of research that receive little ecological discussion, particularly better leadership and administration, recognising that the systems we study out-live the life spans of individual research groups and operate on spatial scales that exceed the capacity of single research providers.
\end{abstract}

KEY WORDS: Urban coast · Turf · Canopy algae $\cdot$ Human impact $\cdot$ Anthropogenic $\cdot$ Nutrient Historical baseline $\cdot$ Habitat loss

Resale or republication not permitted without written consent of the publisher

\section{INTRODUCTION}

What of the natural world is 'natural'? This question motivates a substantial amount of ecological research that seeks to separate natural processes from the overriding influence of human activity in the maintenance of the natural environment (Jackson et al. 2001). The answers are not only central to the science of ecology, but also to the societies that depend on this information for their management of natural resources. In most cases, the answers and forecasted benefits of management (i.e. manipulations of human activities) require knowledge of the 'natural' or original state of a system. The reality, however, is that very little of the 'natural' 
environment is unaffected by human activity, a force that continues to modify and dominate the ecology of most systems (Vitousek et al. 1997). It is problematic that little is understood of past environments, because degradation has gone unrecognised for generations of scientists, and the identification of what was 'natural' becomes increasingly difficult with each passing generation. Indeed, as each generation accepts a progressively more degraded state as 'natural', i.e. the socalled 'shifting-baseline' syndrome (Pauly 1995, Dayton et al. 1998), both scientists and managers continually reduce their expectations of the environment.

The greatest challenge facing the recovery of lost baselines is not so much the science, but a culture of science that is reluctant to accept anecdotal evidence (Pauly 1995). Such conservatism is an important hallmark of science (Kuhn 1996), but is particularly troublesome to the recovery of baselines when few long-term data sets are available for most systems. Although effects of humans may be difficult to separate from natural changes in systems for which disturbances are fundamental to their dynamics (e.g. kelp forests; Connell 2007a), early effects of humans on systems were often quite dramatic (Pauly 1995), and recovering these lost baselines may be possible in many cases.

Globally, there is concern about widespread loss of canopy-forming algae across many parts of the world's rocky coastlines (e.g. Australia, Connell 2007b; Europe, Airoldi \& Beck 2007, America, Steneck et al. 2002). In northern Europe, where coastal inhabitation by large populations of humans has a relatively long history, the loss of large canopies of macroalgae appears to have been permanent (e.g. Baltic Sea, Elmgren 2001; North Sea, Eriksson et al. 2002) and has parallels to the Mediterranean Sea, where tall canopies of macroalgae are puzzlingly rare or under severe regression (e.g. Thibaut et al. 2005, Mangialajo et al. 2008). In this regard, South Australia presents one of the more promising global locations to understand such subtidal change because of its very recent history of major coastal use by humans (i.e. occupation by Europeans since 1836 and accelerated coastal development since the late 1970s).

South Australia's major city has a small metropolitan population (i.e. Adelaide City has 1.2 million people on the eastern side of Gulf St. Vincent), and this presents ecological research with an accessible system in which to study anthropogenic effects over the recent past (e.g. collapse of kelp forests, Jackson et al. 2001). Moreover, the archival evidence needed to reconstruct lost baselines of South Australia's metropolitan subtidal coast is unusually robust for such historical reconstructions. This is because most losses have occurred in recent history, and scientific divers have kept log books of research dives since the 1960s, when subtidal ecology was pioneered with the use of SCUBA (for a review of the early years of subtidal ecology, see Shepherd 2007). In this regard, recovering a lost baseline of subtidal habitat on this particular coast may shed light on other subtidal systems for which human activities are linked to massive changes that took place long before humans donned SCUBA and began studies of subtidal ecology (e.g. Europe, Airoldi \& Beck 2007).

In South Australia, the apparent loss of canopyforming algae on the Adelaide metropolitan coast has been of public concern with continuous years of anecdotal evidence culminating in community groups dedicated to observing subtidal flora and fauna (Reef Watch), reports commissioned by local state agencies (Cheshire et al. 1999) and postgraduate theses that quantified recent loss and experimentally attempted restoration (e.g. Turner 2004). Until now, however, there has been no estimation of the proportion of loss at impacted sites as judged relative to either longerterm historical or broader-scale spatial reference sites. In other words, alternate models about the existence of loss have not been eliminated. This particular lack of evidence has been used by some managers to suggest that historical losses are a myth (S.D.C. \& D.J.T. pers. obs.). That is, there is a view that current sparse patterns of canopies adjacent to urban catchments are 'natural' and probably already existed before the onset of intense coastal urbanisation of the late 1970s.

The key issue, therefore, is to distinguish between 2 equally plausible models, i.e. (1) sparse canopy covers at large urban catchments fall within the natural range of variability in the distribution of canopies in the region and existed before major coastal development of the late 1970s versus (2) sparse canopy covers at large urban catchments do not fall within the natural range of variability of canopy covers in the region and developed after the late 1970s. If the latter model is accepted, the evidence supporting it represents the recovery of a lost baseline that can serve as a basis for future studies that assess whether, or how, these patterns occur as a result of human activity (see Underwood et al. 2000 on logic of observational studies). This paper proceeds in 3 steps by testing hypotheses about the cover of canopy-forming algae at the impacted sites relative to (1) regional patterns across the broader Adelaide coast (Gulf St. Vincent), (2) large geographical patterns across southern Australia's greater province (Flindersian Province), and (3) historical patterns across the last 3 decades (i.e. before and during major coastal development of the late 1970s). This approach not only identifies the magnitude of potential impact by reference to historical data, but also by reference to a population of regional (gulf) and biogeographic (province) sites that comprise the world's longest east-west rocky coastline (i.e. unaffected by north-south gradients). 


\section{MATERIALS AND METHODS}

Urbanisation patterns. The metropolitan coast of Adelaide is centred on the Gulf St. Vincent and is surrounded by rural catchments to the north and south (Fig. 1a). The metropolitan coast is also centred within a catchment (Mt. Lofty catchment) that contains residential housing, along with light and heavy industry. While patches of reef environment occur offshore along the whole length of the metropolitan coastline, it is the southern half with its rocky shores where they are most prevalent. It is also in these southern areas where urban development has been most pronounced over the last 2 decades and, hence, where recent impacts are likely to be detected. Wilkinson et al. (2003) reviewed the history of coastal water pollution discharged from this catchment from 1945 to 2003.
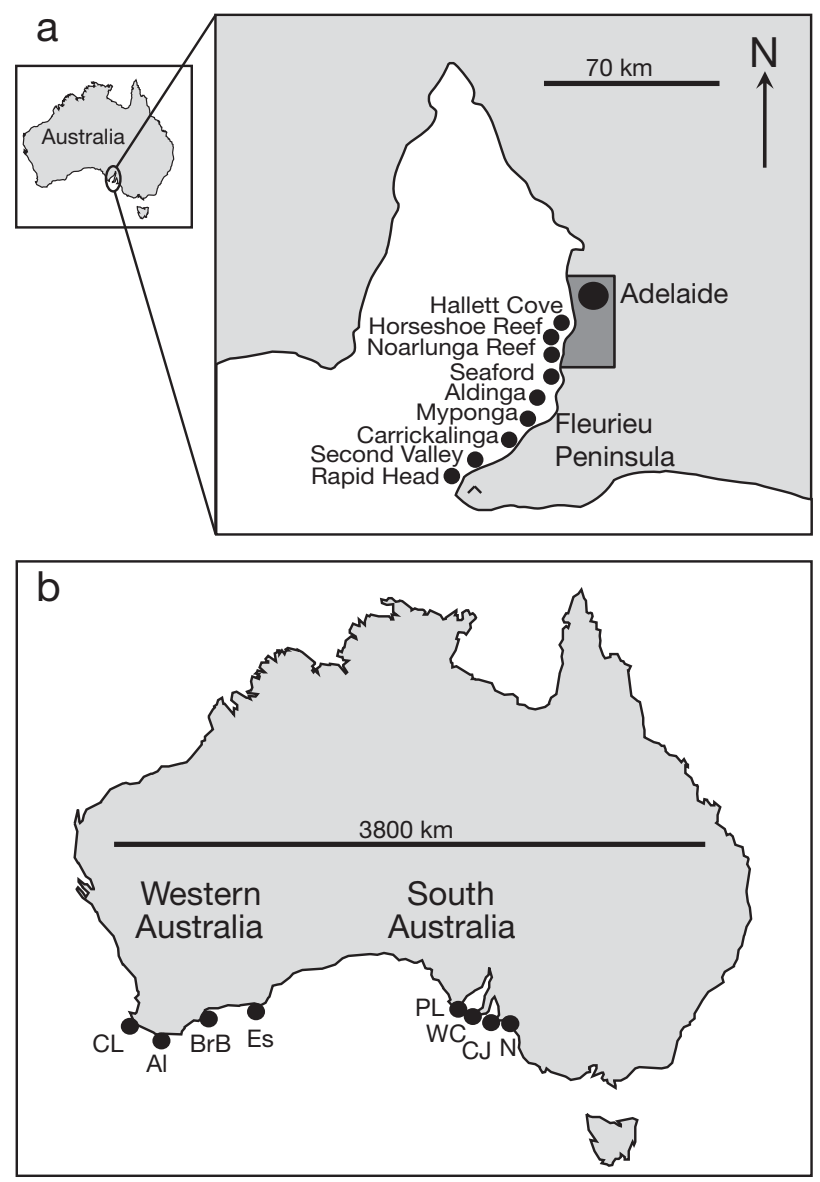

Fig. 1. (a) Gulf St. Vincent, South Australia, showing the sites for regional comparisons of canopy-forming algae, Adelaide City and its metropolitan area (shaded dark grey) and Fleurieu Peninsula. (b) Australia, showing the localities (each containing 3 sites) used for the biogeographic comparisons across the Flindersian Province. CL: Cape Leeuwin, Al: Albany, BrB: Bremer Bay, Es: Esperance, PL: Port Lincoln, WC: West Cape, CJ: Cape Jervis, N: Newland Head
This report stated that a single largest source of landbased pollution is associated with a wastewater treatment plant ( $43 \%$ of land-based discharge in 2003) that was commissioned in 1971, and then initially serviced 13000 people in 1973, and 150000 people by 2003. This plant discharges through an outfall placed $300 \mathrm{~m}$ offshore at $6 \mathrm{~m}$ depth, and volumes of discharge have increased exponentially from no discharge prior to 1973 , then 20452 million litres (ML) to 1980 , then $63485 \mathrm{ML}$ to 1990 , and then another $103891 \mathrm{ML}$ to 2000. Land-based inflow to the coast includes groundwater from the urban catchment (Mt. Lofty catchment) and creek (Christies Creek) from which a natural reed bed was cleared in the early 1970s, and discharge of an estuary (Onkaparinga River, 2 to $3 \mathrm{~km}$ south) on which sewage ponds are located and seepage into the ground water occurs. The population within the urban catchment saw 2 periods of growth and expansion of land use, 1971 to 1981 (33804 to 67365 people, respectively) and 1986 to 1991 (77232 to 132179 people, respectively) (Australian Bureau of Statistics Census Reports). Since 1991, the human population of this catchment has remained relatively stable (2006 population: 149736 people).

The 2 rocky sites considered impacted, Horseshoe Reef and Noarlunga Reef (Fig. 1a), are in close proximity to the outfall ( 1 to $2 \mathrm{~km}$ north), the creek (between both sites and within $\sim 2 \mathrm{~km}$ ) and discharge of the estuary (2 to $3 \mathrm{~km}$ south). These impacted sites are separated by sand, and our observations of them were separated by $>1 \mathrm{~km}$. We recognise that these sites represent pseudo-replicates by virtue of their close proximity and lack of reference sites between them (i.e. the factors affecting them may not be independent). All observations of canopies were taken at 5 to $10 \mathrm{~m}$ depth. The reference sites closest to impacted sites were $>5 \mathrm{~km}$ north (Hallett Cove) and adjacent to an urban catchment, albeit less densely occupied by residential housing due to the position of a large oil refinery, and $>10 \mathrm{~km}$ south (Aldinga Reef), which is also less densely occupied by residential housing. All other sites were adjacent to small rural or natural catchments. We emphasise that we tested hypotheses about whether loss has occurred at the impacted sites and did not seek to test hypotheses about the spatial scale of impact of urbanisation and its relationship to the intensity of land use. The additional data needed to assess whether adjacent reference sites are independent from impacted sites would not greatly improve the differentiation between our primary hypotheses, but would provide a basis for future tests of hypotheses about links between land use and ecology of marine habitats.

Regional patterns. First, we tested the hypothesis that the sparse covers of canopies at the 2 impacted sites do not fall within the natural range of variability 
of canopy covers within the region of Gulf St. Vincent. Canopy cover was estimated on the eastern side of Gulf St. Vincent (City of Adelaide) within 9 sites (spanning $\sim 70 \mathrm{~km}$ ), including the 2 potentially impacted sites on the metropolitan coast (Fig. 1a). The scarcity of rocky shoreline north of Hallett Cove precluded the inclusion of more northerly sites.

Within each of these sites, the size (linear extent) of patches of habitat (see description of habitats below) were quantified using replicate $1 \times 100 \mathrm{~m}$ transects ( $\mathrm{n}=4$ per site) separated by $>10 \mathrm{~m}$. At a $1 \mathrm{~m}^{2}$ scale, habitat was identified as canopy-forming algae where at least 1 individual canopy-forming alga was present. The decision to classify habitat at $1 \mathrm{~m}^{2}$ was based on the knowledge that the covers of canopy-forming algae are negatively related to turf-forming algae at scales of $1 \mathrm{~m}^{2}$ in the presence of mixed-species or monospecific canopies (Irving \& Connell 2006). This negative association has important implications for the subtidal ecology of temperate coasts (see 'Discussion' on turf-forming algae). Transects were oriented perpendicular to the shoreline and started as close to mean low water as the prevailing conditions would allow. The distance along each transect at which the type of habitat changed was recorded, providing information on the relative proportion each habitat occupied under each transect. At sites where the seaward extent of rocky substrata was less than 100 m, sampling ended at that distance. For each habitat quantified, the percentage of the total recorded habitat was calculated (minus any sandy substrate). Asymmetrical 2-way analysis of variance (ANOVA) was used to test for impact (fixed and orthogonal factor) between 2 levels (2 impacted sites versus 7 reference areas), within which the second factor 'sites' (random and nested) had an equal number of levels (i.e. 4 sites) within each area.

Biogeographical patterns. Second, we tested the hypothesis that the sparse covers of canopy-forming species at the 2 impacted sites also fall outside the normal range of variability in canopy distribution across the extended biogeographic province, i.e. the Flindersian Province (Fig. 1 b; $33^{\circ} 37^{\prime} \mathrm{S}$ to $37^{\circ} 06^{\prime} \mathrm{S}$; Connell \& Irving 2008). Within this province, 24 sites about 10 to $1000 \mathrm{~km}$ apart were identified and randomly sampled using the same methods above (i.e. $1 \times 100 \mathrm{~m}$ transects, $\mathrm{n}=4$ per site). To assess the whether this comparison was reasonable (i.e. whether gulf sites could be compared to open coastal sites across Flindersia), we tested for differences in canopy cover between the reference sites in both the gulf ( $\mathrm{n}=7$ sites) and broader province ( $\mathrm{n}=24$ sites). Asymmetrical 2-way ANOVA was used to test for the effect of 'coast' (fixed and orthogonal factor) between the 2 levels ( 7 'gulf' versus 24 'exposed' reference sites), within which the second factor 'sites' (random and nested) had an equal number of levels (i.e. 3 sites) within each type of coast.

Historical patterns. Four co-authors (S.A.S., D.J.T., T.K. and D.M.) had independent data about the past covers of canopy-forming algae at Horseshoe and Port Noarlunga Reefs, the 2 impacted sites. These data originated from 3 very different areas of research enquiry and motivation, and methods of collection. The importance and challenges in the retrieval of historical archival records became apparent in this research (see 'Discussion'). These historical observations were not acquired for the purposes of quantifying patterns of percentage cover of canopies on those reefs, and no formal replicate estimates of cover were taken. All historical observations were made during SCUBA studies of the distribution and relative covers of subtidal habitats in Gulf St. Vincent (methods described below).

The oldest data relate to the percentage cover of canopies in October 1968 (Port Noarlunga) and October 1969 and 1973 (Horseshoe Reef) observed by S.A.S. These data were acquired from qualitative estimates (using SCUBA) of the distribution and relative covers of subtidal habitats in Gulf St. Vincent (Shepherd \& Sprigg 1976). Data from the 1990s were provided by 3 authors (D.J.T., T.K. and D.M.). These data included visual estimates of canopy cover that were recorded in dive log records of D.J.T. (1996) and counts of individual canopy-forming algae per $\mathrm{m}^{2}$ quadrat (1998). Data from 1999 and 2005 where collected within the Reef Health Program (S. Bryars pers. comm.) using a line intercept method (e.g. Turner \& Cheshire 2003) to estimate percentage cover within 4 replicate $20 \mathrm{~m}$ transects at Horseshoe Reef and Port Noarlunga Reef.

Historical records often do not contain estimates of variation, which makes it difficult to use formal statistical tests. Further, in our case, historical data were only available for the impacted sites, preventing a formal direct test of hypotheses of change at impacted versus reference sites. Using an alternative approach, we tested the probability that the historical estimates at impacted sites fell within the current range of variability in the distribution of canopies at regional and biogeographical scales. This test was achieved by comparing historical impacted estimates to the $95 \%$ confidence limits of the standard normal distribution of estimates across the gulf (regional scale) and the province (biogeographical scale). We transformed the upper and lower boundary of the standard normal distribution (which we set at the convention of 0.05) to the equivalent boundaries for the normal distribution of our mean and variance of regional and biogeographical estimates. This calculation identifies the critical values that define the statistical null hypothesis (i.e. region of rejection). If our historical estimates fell within the range of null values, historical canopy cov- 
ers at impacted sites would be equivalent to contemporary canopy covers at regional and biogeographical scales. This result would not support the model that current sparse canopy covers at impacted sites existed historically. Alternatively, if historical estimates fell outside the range of null values, historical canopy covers at impacted sites would be different from contemporary canopy covers at regional and biogeographical scales. This result would support the model that canopy covers at impacted sites were historically different from canopy covers at regional and biogeographical scales.

Contemporary patterns of water quality at regional and local scales. Water quality was observed at the 2 impacted (Horseshoe Reef and Noarlunga Reef) and 2 reference sites, 1 to the north (Hallett Cove) and 1 to the south (Aldinga Reef). Within each of these sites, we quantified nitrogen $\left(\mathrm{NO}_{\mathrm{x}}\right)$, chlorophyll (chl) $a$ and turbidity (Secchi depth). For $\mathrm{NO}_{\mathrm{x}}$, water samples were collected in separate sterile $250 \mathrm{ml}$ vials ( $\mathrm{n}=3$ per site), acidified with $1 \mathrm{ml}$ of $\mathrm{H}_{2} \mathrm{SO}_{4}$ for transport, and analysed using a flow injection analyser. For chl $a, 11$ samples were collected in separate sterile bottles ( $\mathrm{n}=3$ per site), filtered through Whatman GF/F filters, digested with $100 \%$ ethanol, and analysed in a spectrophotometer for concentration of $\mathrm{chl} \mathrm{a}\left(\mathrm{mg} \mathrm{l}^{-1}\right)$. Secchi depth was measured using a Secchi disc to assess the depth at which its image was extinguished ( $\mathrm{n}=3$ deployments per site). Data were collected during May and June, the time of year when periods of rainfall are often greatest (winter months; June to August).

Comparisons across space, time and taxonomy. Natural variation in space, time and taxonomy and scales at which we observe them is a subtle source of conflict in marine ecology (Connell 2007a) but a conspicuous source of concern for historical reconstructions because of the prominence of historical and environmental variation that may confound comparisons. With respect to potential biases, this section provides details of prominent variation associated with space (i.e. wave exposure), time (i.e. timing of sampling) and taxonomy (i.e. covers of constituent species) between our impacted and reference sites.

Spatially, the most conspicuous environmental difference among comparisons centres on the lower wave exposure of the metropolitan coast (gulf coast) than its broader province (open coast). This natural variation would bias our comparison in favour of the hypothesis of loss if canopy gaps are naturally more extensive on sheltered than exposed coasts. In South Australia, however, canopy gaps are naturally smaller on wavesheltered than exposed coasts (Wernberg \& Connell in press), a pattern that is opposite that predicted for coasts considered to be more susceptible to human activity (i.e. sheltered coasts, Connell 2007b). These observations suggest that natural variation (exposure) would bias comparisons against our capacity to distinguish impacted sites from reference sites (i.e. a conservative test of the null-hypothesis of no difference). Differences in depth are unlikely to account for differences between impacted and reference sites, as all sampling started shallow (within $1 \mathrm{~m}$ of low water) and finished at a similar average depth (impacted = $7.8 \pm 1.7 \mathrm{~m}$, reference for regional sites $=8.1 \pm 0.6$, and reference for biogeographic sites $=9.0 \pm 0.5 \mathrm{~m}$ ).

Temporally, unrecognised variation at smaller scales (e.g. seasonal variation among alternate data sets) may confound broader scale patterns (e.g. interpretations of decadal decline). In our case, such confounding could apply to species of canopy-forming algae that undergo large seasonal variation, namely some species of Sargassum that can lose their entire canopy during their non-reproductive season. In South Australia, canopies comprise many species (Acrocarpia, Caulocystis, Cystophora, Ecklonia, Scaberia, Scytothalia, Seirococcus and Sargassum), but the most common and widespread canopies are perennial (i.e. E. radiata and Cystophora species). For every $1 \mathrm{~m}^{2}$ of rock covered by canopy, our results revealed that E. radiata occurs across $51 \%$ of the rocky Gulf and $67 \%$ of the broader rocky coastline of the Flindersian Province, with fucoids monopolising the remaining proportion. If our test of differences between impacted and reference sites was biased by seasonal variation, we would have needed to sample the temporal and spatial reference sites in seasons of naturally extensive cover, and contemporary impacted sites in seasons on naturally sparse cover. Our sampling did not match these conditions of bias.

Of the 3 species of Sargassum present at impacted sites, $S$. decipiens loses some laterals from austral midsummer to late autumn, $S$. spinuligerum loses very little canopy from summer to autumn (Womersley 1987) and S. fallax (sub nom. S. bracteolosum) loses buoyancy in mid-summer, leaving only basal leaves during autumn, before reappearing in winter until mid-summer (Edgar 1983). The oldest sampling of impacted sites was done in the fertile season (mid-winter to late spring) as was the contemporary sampling of impacted sites (mid-winter to early-summer). Contemporary sampling of reference sites (both biogeographic and regional) occurred in mid- to late summer, when canopies were absent or sparse (i.e. sterile season of mid-summer to late autumn; Womersley 1987), but the impacted sites were sampled during the fertile period (mid-winter to early summer), when canopies were present and extensive. This latter comparison would bias against detecting differences between impacted and reference sites, and therefore provides a conservative test and estimate of loss. 


\section{RESULTS}

\section{Contemporary versus historical patterns at regional scales}

Comparison of contemporary north-south covers of canopy algae along the gulf revealed that the 2 impacted sites had sparser covers than comparable gulf sites within the region (Fig. 2; asymmetrical 2-way ANOVA $\left.; F_{1,7}=53.12, \mathrm{p}<0.001\right)$. Contemporary covers at impacted sites (Horseshoe and Noarlunga Reefs, 15.3 and $20.3 \%$, respectively) fell outside the $95 \%$ confidence intervals $(61.6 \%$ to $100 \%)$ of the standard normal distribution of estimates across the gulf, also identifying impacted sites to be different from reference sites.

Historically, the 2 impacted locations rank at third (Noarlunga) and seventh (Horseshoe Reef) highest estimates of proportional cover of canopies among the 9 sites (Fig. 2; cf. historical versus contemporary estimates). We tested how likely or unlikely these impacted covers could represent a subset within the population of regional sites. Historical estimates (Horseshoe and Noarlunga Reefs, 80 and $90 \%$, respectively) fell within the region of the null hypothesis (61.6 to $100 \%$ ), and thereby suggest that historical covers at impacted sites could represent a random subset of sites in the gulf today. Therefore, the difference between contemporary impacted sites and the other locations in the region can be interpreted as a historical loss of canopy-forming algae of approximately 71 and $67 \%$ at Horseshoe Reef and Port Noarlunga, respectively. Similarly, the difference between historical and contemporary estimates at im-

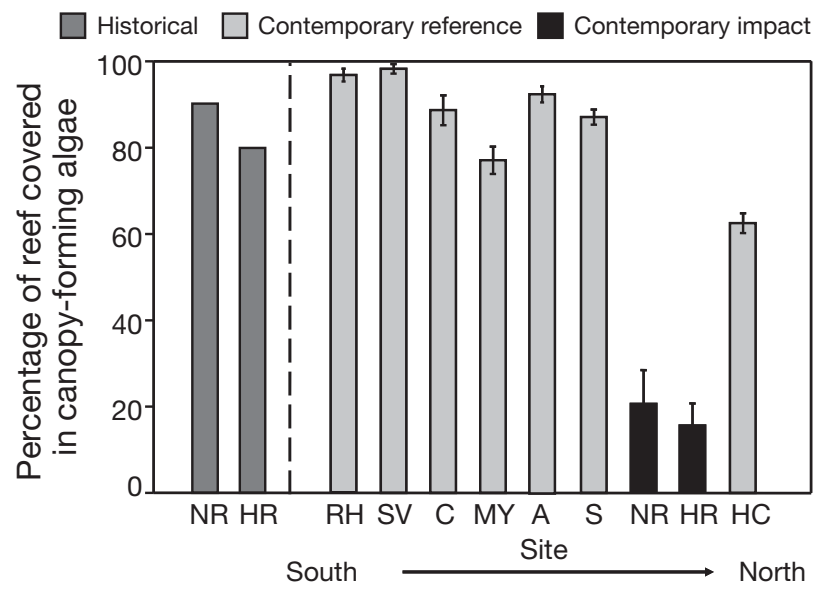

Fig. 2. Historical and contemporary cover of canopy-forming algae (mean \pm SE of percentage cover) on impacted and reference rocky reefs in Gulf St. Vincent, South Australia. No error bars are presented for the historical covers that are single estimates. NR: Noarlunga Reef, HR: Horseshoe Reef, RH: Rapid Head, SV: Second Valley, C: Carrackalinga, MY: Myponga, A: Aldinga, S: Seaford, HC: Hallett Cove pacted sites may also represent an additional estimate of temporal change (Fig. 3), i.e. 65 and $70 \%$ loss at Horseshoe Reef and Port Noarlunga, respectively. In addition, the density of individual canopy-formers was observed to become $70 \%$ sparser between 1999 and 2001 at these impacted sites (i.e. from $20 \mathrm{~m}^{2}$ to $6 \mathrm{~m}^{2}$ ), but not at 4 reference sites, i.e. 1 site located to the north (Hallet Cove) and 3 sites located to the south (Southport Reef, and 2 reefs off Moana South; Turner 2004).

Water quality at the impacted sites was lower than that of the reference sites (Table 1). In their regional context, these metropolitan $\left[\mathrm{NO}_{\mathrm{x}}\right]$ concentrations exceed the South Australian state water quality limits of $0.20 \mathrm{mg} \mathrm{l}^{-1}$ (Environmental Protection Authority 2003), as additionally observed during periods of light rainfall $\left(0.481 \pm 0.038 \mathrm{mg} \mathrm{l}^{-1}\right)$ and heavy rainfall $\left(0.631 \pm 0.022 \mathrm{mg} \mathrm{l}^{-1}\right)$ near Horseshoe Reef (D. Gorman, B.D.R., S.D.C. unpubl. data from 2005 and 2006). These concentrations are several times greater than those observed in marine waters adjacent to agricultural catchments $\left(0.12 \pm 0.02 \mathrm{mg} \mathrm{l}^{-1}, \mathrm{n}=4\right.$ catchments $)$ and natural catchments $\left(0.001 \mathrm{mg} \mathrm{l}^{-1}, \mathrm{n}=4\right.$ catchments) of the greater Fleurieu Peninsula (D. Gorman, B.D.R. \& S.D.C. unpubl. data from 2005 and 2006). Secchi visibility was ranked shallower at impacted than reference sites in 16 of 18 observations (T. S. Elsdon \& S.D.C. unpubl. data from 2007).

\section{Contemporary versus historical patterns at biogeographic scales}

Historical estimates at impacted sites could also represent a subset of sites across the biogeographic province today (Fig. 4; cf. historical versus contemporary estimates). Historical estimates (80 and 90\%) fell within the region of the null hypothesis ( 74.4 to $100 \%$ ), suggesting that historical covers at impacted sites can

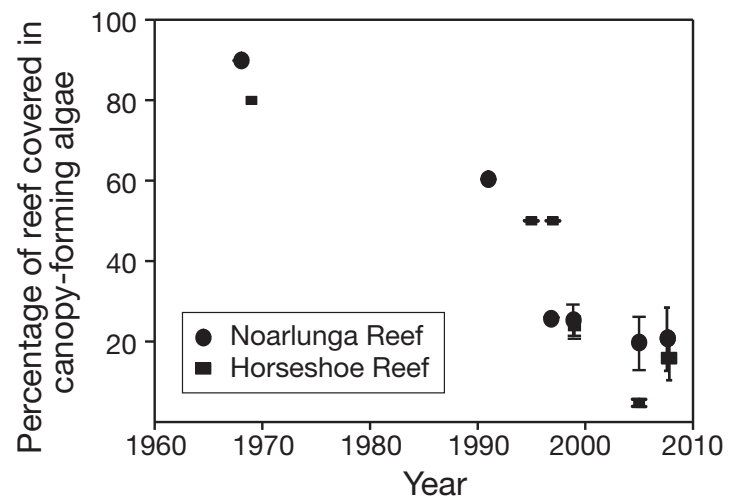

Fig. 3. Change in the percentage cover of canopy-forming algae (1969 to 2007) at the 2 impacted sites on the metropolitan coast of Adelaide 
Table 1. Observations of water quality (mean \pm SEM) among impacted and reference sites ( $n=3$ observations per site) during a rainfall event in 2007. See 'Results' for comparison of these results to additional sampling times, noting that the $\mathrm{NO}_{\mathrm{x}}$ concentrations exceed the South Australian state water quality limits of $0.20 \mathrm{mg} \mathrm{l}^{-1}$ (Environmental Protection Authority 2003). ANOVA detected all parameters to be greater at impacted sites than reference sites $\left(F_{3,8}, \mathrm{p}<0.05\right)$. Lower values for Secchi depth correspond to greater turbidity

\begin{tabular}{|lcccc|}
\hline $\begin{array}{l}\text { Impact/ } \\
\text { Reference }\end{array}$ & Site & $\begin{array}{c}\text { Nitrogen } \\
\left(\mathrm{NO}_{\mathrm{x}}, \mathrm{mg} \mathrm{l}^{-1}\right)\end{array}$ & $\begin{array}{c}\text { Turbidity } \\
(\text { Secchi depth, } \mathrm{m})\end{array}$ & $\begin{array}{c}\mathrm{Chl} \mathrm{a} \\
\left(\mu \mathrm{l} \mathrm{l}^{-1}\right)\end{array}$ \\
\hline Impact & Horseshoe Reef & $0.522 \pm 0.107$ & $3.2 \pm 0.152$ & $15.75 \pm 2.45$ \\
Impact & Noarlunga Reef & $0.274 \pm 0.173$ & $2.9 \pm 0.190$ & $15.29 \pm 0.80$ \\
Reference & Hallett Cove & $0.0392 \pm 0.003$ & $7.3 \pm 1.45$ & $8.34 \pm 0.80$ \\
Reference & Aldinga & $0.025 \pm 0.0039$ & $5.9 \pm 0.67$ & $9.27 \pm 0.46$ \\
\hline
\end{tabular}

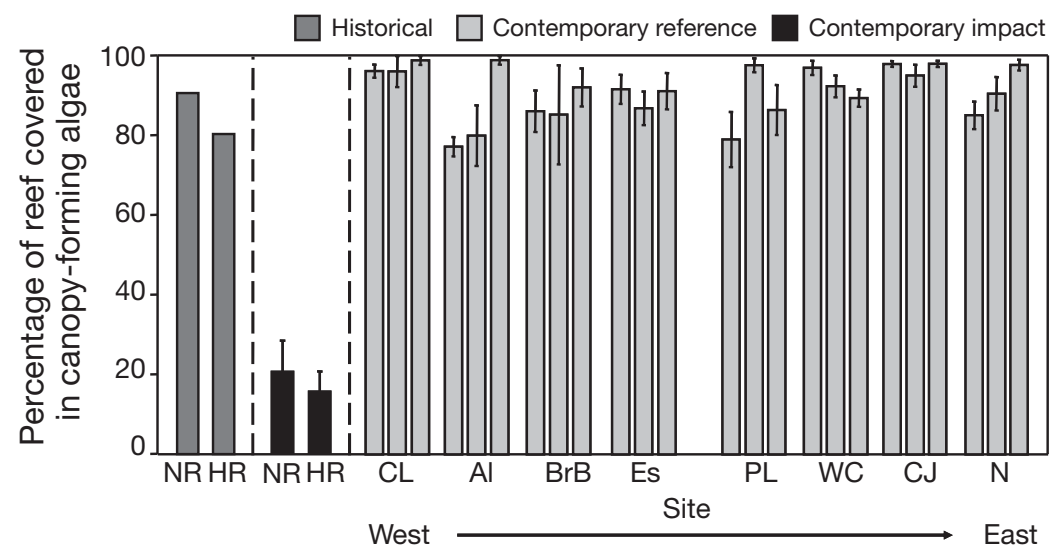

Fig. 4. Comparison of the historical and contemporary covers of canopy-forming algae (mean $\pm \mathrm{SE}$ ) on impacted and reference rocky sites across Western Australia and South Australia. Data are presented for 3 sites within each locality. NR: Noarlunga Reef, HR: Horseshoe Reef, RH: Rapid Head, CL: Cape Leeuwin, Al: Albany, BrB: Bremer Bay, Es: Esperance, PL: Port Lincoln, WC: West Cape, CJ: Cape Jervis, N: Newland Head. No error bars are presented for the historical covers that are single estimates

represent a random subset of reference sites across $2100 \mathrm{~km}$ of the continent. This comparison is reasonable on the basis that covers of canopies among reference sites in the gulf were not distinguishable from those of the broader province (asymmetrical 2-way ANOVA: $F_{1,29}=2.00, \mathrm{p}=0.18$ ).

\section{DISCUSSION}

The key result is that historically, the impacted metropolitan sites were indistinguishable from the contemporary population of regional sites $(\sim 70 \mathrm{~km}$ of the gulf), and could also represent a random subset of open coastal sites across the greater province of Flindersia ( $2100 \mathrm{~km}$ of coast). This evidence suggests that there was nothing 'special' about the impacted sites historically, but today they stand out because they have sparser covers of canopies compared to equiva- lent locations and times in the gulf and the greater province. Contemporary covers at the impacted sites are 65 to $70 \%$ less than surrounding sites, and our evidence rejects the model that this pattern existed before major coastal development (i.e. since increasing urbanisation of the late 1970s). We interpret these patterns as evidence of loss of canopy-forming algae on the Adelaide metropolitan coast (Fig. 5).

The modern challenge is to understand the conditions and mechanisms that lead to habitat loss, with the intent of predicting or preventing future losses. We recognise models of habitat loss that centre on harvesting, where deforestation occurs by direct harvesting of canopies (Castilla et al. 2007), or overharvesting of vertebrate predators that triggers an increase in herbivore populations and the overconsumption of algal canopies (Steneck et al. 2002). The direct harvesting of seaweeds, however, does not occur on the Adelaide metropolitan coast and is not a model commonly used to explain the widespread and long-term losses observed globally. More commonly used models centre on the influence of fishing (trophic cascades or top-down models) and have the capacity to account for the presence and absence of canopies in eastern Australia (Peronian Province), but has extremely limited capacity in the region we studied (Flindersian Province; Connell \& Irving 2008). Instead, Flindersian models centre on changes to water quality (Connell 2007b) and share a common basis with other systems that have documented long-term and widespread loss across human-dominated coasts (e.g. Baltic Sea, Elmgren 2001; North Sea, Eriksson et al. 2002).

Ecological theory predicts that human-dominated environments favour small fast-growing or 'weedy' species that are able to displace slower-growing species (Tilman \& Lehman 2001). This model appears to be applicable to human-dominated coasts, such as the Adelaide metropolitan coast, where canopy-forming algae have undergone widespread replacement by turf-forming species that trap large amounts of sediment (present paper on canopies; Gorgula \& Connell 2004 on turfs). The novel environments created by human pollution (e.g. sedimentation and eutrophication) do not appear to have direct negative effects on canopies, but rather act in conjunction with natural 

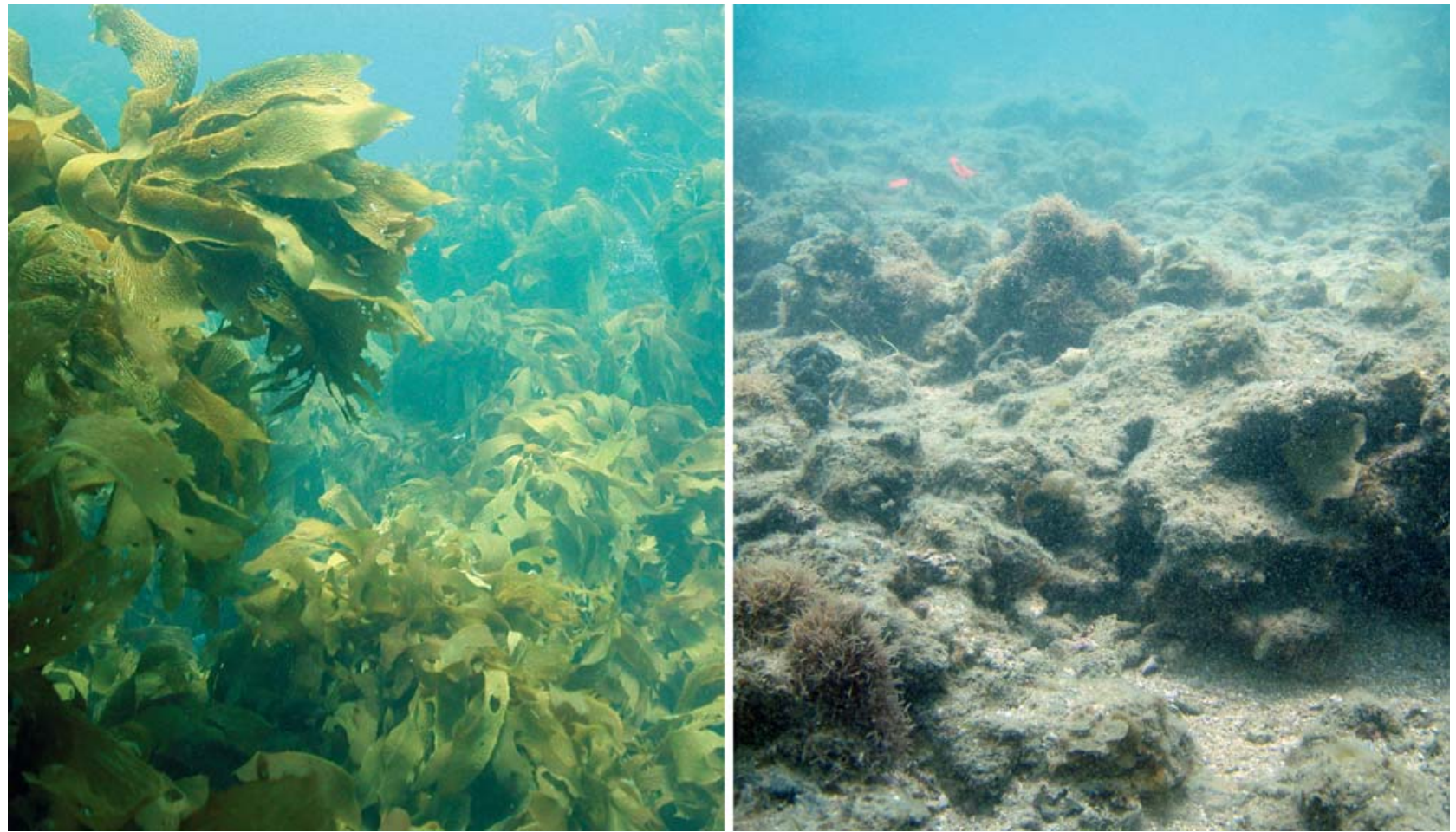

Fig. 5. Canopy-forming algae characterise most temperate coasts (e.g. kelp forests pictured on the left), but some forests have been replaced by extensive covers of turf-forming algae (e.g. the Adelaide metropolitan coast on the right). Models that account for this switch from topographically complex and productive habitat to simpler and less productive habitat are needed if we are predict or manage against future change. Photographs by S.D.C.

disturbances that remove canopies (e.g. storms) to create conditions needed for the rapid colonisation by turfs that accumulate sediment (Irving \& Connell 2006). These short, densely packed turfs have limited capacity to store nitrogen and are normally ephemeral (Pedersen \& Borum 1996), but persist under conditions of high nutrient and sediment loads (Gorgula \& Connell 2004). A key condition is sediment accumulation, which inhibits the recruitment of kelp (Devinny \& Volse 1978). Vulnerable localities appear to be associated with conditions that enhance sediment deposition (e.g. dredging and intensive land use) or sediment accumulation (e.g. rocky substratum that is low-lying and of low relief or in close proximity to sand or covered in turfs). Turfs can inhibit kelp recruitment (Kennelly 1987) and its experimental removal can increase kelp recruitment after 12 mo (D. Gorman \& S.D.C. unpubl. data), possibly because of the large amount of sediment they trap (reviewed by Airoldi 2003). On some coasts, this switch between canopy and turfforming algae may not be reversed over several generations of canopy-forming taxa (Benedetti-Cecchi et al. 2001, Eriksson et al. 2002).

This model of human modification of water chemistry and ensuing habitat shifts (above) may prove to be very general, but we warn against its uncritical use. Some of the most compelling evidence for this model is derived from enclosed seas (e.g. bays and gulfs) that are fringed by populations of humans and heavy industry, thereby restricting circulation of water bodies of degraded quality (e.g. Baltic Sea, Elmgren 2001; North Sea, Eriksson et al. 2002). Indeed, there is growing recognition of the ecological contexts (e.g. biogeography and geomorphology) that make some coastal systems more vulnerable, and others more resistant, to increasing human-domination of the world's coastlines (e.g. Connell \& Irving 2008). We, therefore, highlight the unreasonable use of the logical argument that human population size is proportional to the magnitude and onset of human-driven change to biogenic habitats. Human activities that alter water chemistry and consumption rates of herbivores are unlikely to act independently of natural variation in coastal productivity (e.g. rates of natural gain of biomass by production) and functional types of their consumers (e.g. rates of natural loss of biomass to herbivores). For example, spatial differences in coastal nutrient concentrations alter the magnitude of ecological response to sudden increases in nutrient concentrations (e.g. run-off; Russell \& Connell 2007) and account for disproportionately 
larger responses of nutrient enrichment on nutrientpoor coasts (Russell et al. 2005, S. D. Connell et al. unpubl. data).

Future progress may rely on some productive debate about methodology. One of the most recurring methodological issues centres on the choice of variables we use to observe the response of ecosystems to their human assaults (e.g. molecules, species, groups, habitats). Our work specifically tested hypotheses about canopies as a habitat and not about their component species. We recognise that the use of alternate classifications (e.g. morphology versus species) and indices (e.g. Shannon index versus ABC curves versus phylogenetic relatedness) largely predetermine our perception of ecological change and prediction of future environments (Roberts \& Connell 2008). There is little wonder, therefore, that subtidal ecologists researching similar systems will alternately highlight the information lost (Phillips et al. 1997) or the information gained with the use of broader-based classifications (Anderson et al. 2005) with particular methods of classification. In this regard, there would be some value in understanding the costs and benefits of using alternate classifications in descriptions of ecological changes that concern societal perceptions.

In conclusion, forecasted changes to abiotic environments at local and global scales (Harley et al. 2006) may be compounded by historical changes that have gone unnoticed. There has, therefore, never been a more pressing need for longer-term datasets to interpret the influence of human activities. The predominance of research focusing on local spatial scales over short time scales appears particularly counterproductive to our ability to detect change. While acquiring data for this research, we also identified that some of the greatest challenges to longer-term datasets may not be scientific. The storage and retrieval of data has become increasingly more problematic as rapid improvements in technology (e.g. computer software and hardware) chain current archival efforts to antiquated technology. Already, some 'modern' technology has become redundant, so that stored information is impossible to retrieve (e.g. tape drives and specific kinds of image projectors that no longer exist). Perhaps clay tablets that record human history represent some of our longest lasting archival media (albeit of low storage capacity) that capture change on time-scales we are becoming more aware of and increasingly concerned about (e.g. climate change).

Finally, we emphasise the lack of coherent research across time, matched by discordant research across space and taxonomic scales, and a need for a broader vision by those charged with the administration of science (i.e. its accountability and fundability). Indeed, never has there been a greater need for better leader- ship of the ecological sciences. The discipline of ecology needs leadership that encourages rather than penalises collaboration and inheritance of data. Our life spans are often less than the duration of the organisms we study, and our expertise and capacity to research multiple localities and levels of biological organisation are limited. We are not naïve in understanding that institutional reform is difficult and slow, and good leaders occur infrequently across generations; hence, we encourage some of this progress to fall on the shoulders of individuals with an ability to focus on collective rather than personal goals, and on longterm progress. Indeed, many of the environmental changes we only now recognise were set in motion long ago.

Acknowledgements. Over many years, this project was assisted by numerous people and supported by research funding from the Department of Environment and Heritage, National Land and Water Resources Audit, FRDC Reef Health Project, Australian Research Council, SA Environmental Protection Authority and SA Water. This manuscript benefited from network discussions within the ARC Environmental Futures Network. International support was given by a Marco Polo grant from the Università di Bologna to L.A. The cooperation among authors reflects a common bond and pioneering spirit caused by the common dangers and limitations of working under temperate seas. We acknowledge The University of Adelaide, which forged Australian subtidal ecology in the 1950s (with home-made SCUBA) and subsequently supported and safeguarded SCUBA as a research tool for its staff, students and all authors here.

\section{LITERATURE CITED}

Airoldi L (2003) The effects of sedimentation on rocky coast assemblages. Oceanogr Mar Biol Annu Rev 41:161-236

Airoldi L, Beck MW (2007) Loss, status and trends for coastal marine habitats of Europe. Oceanogr Mar Biol Annu Rev 45:345-405

Anderson MJ, Connell SD, Gillanders BM, Diebel CE, Blom WM, Saunders JE, Landers TJ (2005) Relationships between taxonomic resolution and spatial scales of multivariate variation. J Anim Ecol 74:636-646

Benedetti-Cecchi L, Pannacciulli F, Bulleri F, Moschella PS, Airoldi L, Relini G, Cinelli F (2001) Predicting the consequences of anthropogenic disturbance: large-scale effects of loss of canopy algae on rocky shores. Mar Ecol Prog Ser 214:137-150

Castilla JC, Campo MA, Bustamante RH (2007) Recovery of Durvillaea antarctica (Durvilleales) inside and outside Las Cruces marine reserve, Chile. Ecol Appl 17:1511-1522

Cheshire AC, Miller DJ, Stewart R (1999) Effect of dispersed sediment plumes from beach and sand replenishment dredging on recruitment of phaeophycean algae to rocky reefs in Gulf St. Vincent, South Australia. A report to the Environmental Protection Authority of South Australia. Department of Environmental Biology, University of Adelaide

Connell SD (2007a) Subtidal temperate rocky habitats: habitat heterogeneity at local to continental scales. In: Connell SD, Gillanders BM (eds) Marine ecology. Oxford University Press, Melbourne, p 378-401 
Connell SD (2007b) Water quality and the loss of coral reefs and kelp forests: alternative states and the influence of fishing. In: Connell SD, Gillanders BM (eds) Marine ecology. Oxford University Press, Melbourne, p 556-568

Connell SD, Irving AD (2008) Integrating ecology with biogeography using landscape characteristics: a case study of subtidal habitat across continental Australia. J Biogeogr doi:10.1111/j.1365-2699.2008.01903.x

Dayton PK, Tegner MJ, Edwards PB, Riser KL (1998) Sliding baselines, ghosts, and reduced expectations in kelp forest communities. Ecol Appl 8:309-322

Devinny JS, Volse LA (1978) Effects of sediments on the development of Macrocystis pyrifera gametophytes. Mar Biol 48:343-348

Edgar GJ (1983) The ecology of south-east Tasmanian phytal animal communities. II. Seasonal change in plant and animal populations. J Exp Mar Biol Ecol 70:159-179

Elmgren R (2001) Understanding human impact on the Baltic ecosystem: changing views in recent decades. Ambio 30: $222-231$

Environment Protection Authority (2003) Environment protection (water quality) policy 2003 and explanatory report, Environment Protection Authority, Adelaide

Eriksson BK, Johansson G, Snoeijs P (2002) Long-term changes in the macroalgal vegetation of the inner Gullmar Fjord, Swedish Skagerrak coast. J Phycol 38:284-296

Gorgula SK, Connell SD (2004) Expansive covers of turf-forming algae on human-dominated coast: the relative effects of increasing nutrient and sediment loads. Mar Biol 145: 613-619

Harley CDG, Hughes AR, Hultgren KM, Miner BG and others (2006) The impacts of climate change in coastal marine systems. Ecol Lett 9:228-241

Irving AD, Connell SD (2006) Physical disturbance by kelp abrades erect algae from the understorey. Mar Ecol Prog Ser 324:127-137

Jackson JBC, Kirby MX, Berger WH, Bjorndal KA and others (2001) Historical overfishing and the recent collapse of coastal ecosystems. Science 293:629-638

Kennelly SJ (1987) Inhibition of kelp recruitment by turfforming algae and consequences for an Australian kelp community. J Exp Mar Biol Ecol 112:49-60

Kuhn TS (1996) The structure of scientific revolutions. The University of Chicago Press, Chicago, IL

Mangialajo L, Chiantore M, Cattaneo-Vietti R (2008) Loss of fucoid algae along a gradient of urbanisation, and structure of benthic assemblages. Mar Ecol Prog Ser 358:63-74

Pauly D (1995) Anecdotes and the shifting base-line syndrome of fisheries. Trends Ecol Evol 10:430

Pedersen MF, Borum J (1996) Nutrient control of algal growth in estuarine waters. Nutrient limitation and the importance of nitrogen requirements and nitrogen storage among phytoplankton and species of macroalgae. Mar Ecol Prog Ser 142:261-272

Phillips JC, Kendrick GA, Lavery PS (1997) A test of a functional group approach to detecting shifts in macroalgal

Editorial responsibility: Morten Pederson,

Roskilde, Denmark communities along a disturbance gradient. Mar Ecol Prog Ser 153:125-138

Roberts BK, Connell SD (2008) Detecting benthic responses to human-induced change: effectiveness of alternate taxonomic classification and indices. Mar Ecol Prog Ser 358: $75-84$

Russell BD, Connell SD (2007) Response of grazers to sudden nutrient pulses in oligotrophic versus eutrophic conditions. Mar Ecol Prog Ser 349:73-80

Russell BD, Elsdon TS, Gillanders BM, Connell SD (2005) Nutrients increase epiphyte loads: broad-scale observations and an experimental assessment. Mar Biol 147: 551-558

Shepherd SA (2007) The early years of subtidal ecology. In: Connell SD, Gillanders BM (eds) Marine ecology. Oxford University Press, Melbourne, p 614-615

Shepherd SA, Sprigg RC (1976) Substrate, sediments and subtidal ecology of Gulf St Vincent and Investigator Strait. In: Twidale CR (ed) Natural history of the Adelaide region. Royal Society of South Australia, Adelaide, p 162-172

Steneck RS, Graham MH, Bourget BJ, Corbett D, Erlandson JM, Estes JA, Tegner MJ (2002) Kelp forest ecosystems: biodiversity, stability, resilience and future. Environ Conserv 29:436-459

Thibaut T, Pinedo S, Torras X, Ballesteros E (2005) Long-term decline of the populations of Fucales (Cystoseira spp. and Sargassum spp.) in the Albères coast (France, North-western Mediterranean). Mar Pollut Bull 50:1472-1489

> Tilman D, Lehman C (2001) Human-caused environmental change: impacts on plant diversity and evolution. Proc Natl Acad Sci USA 98:5433-5440

Turner DJ (2004) Effects of sedimentation on the structure of a phaeophycean dominated macroalgal community. $\mathrm{PhD}$ thesis, University of Adelaide

Turner DJ, Cheshire AC (2003) Encounter 2002 expedition to the Isles of St Francis, South Australia: structure and productivity of benthic macroalgal communities. Trans R Soc S Aust 127:153-166

> Underwood AJ, Chapman MC, Connell SD (2000) Observations in ecology: You can't make progress on processes without understanding the patterns. J Exp Mar Biol Ecol 250:97-115

Vitousek P, Mooney H, Lubchenco J, Melillo J (1997) Human domination of earth's ecosystems. Science 277:494-499

Wernberg T, Connell SD (in press) Physical disturbance and subtidal habitat structure on open rocky coasts: effects of wave exposure, extent and intensity. J Sea Res, doi:10. 1016/j.seares.2008.02.005

Wilkinson J, Pearce M, Cromar N, Fallowfield H (2003) Audit of the quality and quantity of treated wastewater discharging from wastewater treatment plants (WWTPs) to the marine environment. Department of Environmental Health, Flinders University of South Australia, Adelaide

Womersley HBS (1987) The marine benthic flora of Southern Australia, Part II. South Australian Government Printing Division, Adelaide

Submitted: December 6, 2007; Accepted: April 14, 2008

Proofs received from author(s): May 15, 2008 